\title{
Dynamic bending behaviour of woven composites for sports products: Experiments and damage analysis HIMAYAT ULLAH ${ }^{1}$, ANDY R. HARLAND, VADIM V. SILBERSCHMIDT*
}

Wolfson School of Mechanical and Manufacturing Engineering, Loughborough University, Leicestershire, LE11

$3 T U, U K$

*Corresponding author: Ashby Road, Loughborough, Leics., LE11 3TU, UK. Phone: +44 1509227504.

Fax: +44 1509 227502, Email: V.Silberschmidt@lboro.ac.uk

${ }^{1}$ Present address: National University of Sciences and Technology, College of E\&ME, Peshawar Road, Islamabad, Pakistan; Email: uhimayat@gmail.com

\section{ABSTRACT}

Carbon fabric-reinforced polymer (CFRP) laminates employed in sports products are usually subjected to largedeflection quasi-static and dynamic bending deformations during service. Such loading conditions induce damage in the material, affecting its strength, stiffness and energy-absorbing capability. To study this, mechanical behaviour of woven CFRP composites in on- and off-axis orientations is first quantified by carrying out large-deflection quasi-static bending tests followed by dynamic ones employing an Izod-type impact tester. CFRP laminates of various orientations were tested at loads increasing up to failure to determine their energyabsorbing capability. On-axis laminates demonstrated better strength and stiffness whereas off-axis laminates exhibited good energy-absorbing capability. However, for applications demanding strength, stiffness and energy absorption as in sports products, a combination of both types of plies, as in a quasi-isotropic layup, is an optimum choice. Micro-computed tomography (micro-CT) analysis of the tested specimens showed that matrix cracking, delamination and tow debonding were the dominant damage modes at the specimen's impact location, whereas fabric fracture occurred at the bending location. Further, a catastrophic brittle fracture was observed in the on-axis laminates whereas the off-axis laminates exhibited pseudo-ductile behaviour thanks to matrix cracking and fibre trellising before their failure at higher energies.

Keywords: CFRP; Dynamic bending; micro-CT, Delamination; Fracture

\section{Introduction}

Woven composites such as CFRP laminates are increasingly used in aerospace, automotive and energy components and structures thanks to their higher impact resistance and damage tolerance and better manufacturability as compared to unidirectional laminates [1]. Improvements in manufacturing processes and cost reduction caused an extensive use of composites in sporting goods ranging from tennis rackets, skis, sports gears, sports bicycles, hockey sticks, baseball and cricket bats, fishing rods, oars and paddles, archery bows to running shoes. In many of these applications, composites are replacing traditional materials such as metals, wood and leather thanks to their higher specific strength, specific stiffness, weight reduction, energy absorption, vibration damping as well as improved design and manufacturing flexibility [2]. Importantly, these material properties result in performance improvements that enable athletes to compete at a higher level with less effort and fatigue. For example, lighter composite structures result in higher speeds and quicker manoeuvring in bicycle and boat racing; lighter and stiffer tennis rackets and golf clubs can hit the ball faster and farther with more comfort, while better toughness and vibration damping in sports shoes can result in faster and longer 
running by athletes. In athletic footwear insoles, composite laminates are nowadays used to enhance the runner's comfort thanks to the material's better energy absorption and fewer injuries thanks to better impact resistance [3].

Footwear is subjected to repeated impacts as the heel strikes the ground during running. As shown in Fig. 1, a typical vertical reaction force with two peaks is generated in heel-strike during running. The first peak known as the passive load cannot be cushioned by human movement as its duration is too short for a human to make a cushioning movement. Hence, since this impact load is considered as the source of injuries, it needs to be cushioned by a shoe material [4]. Further, the peak forces generated during a heel strike are 2-3 times the runner's body weight, and the number of impacts is around 1500 per mile, varying between subjects [5]. Due to repetitive impacts and high loading rates in running, it is more likely that injuries occur to the bones and tissues of human legs. Therefore, among the main design requirements for athletic footwear are impact and shock resistance, better damping and energy absorption, higher strains to failure and strain rates, higher stiffness and light weight for better comfort of runners. Nowadays, sports industry focuses on innovations in sports shoes in areas of materials, motion control of foot, mass and athletics design. Carbon fabric together with the embedding thermoplastic polyurethane matrix offers these unique properties to footwear insoles. Thin strips of CFRP laminates are sandwiched in the midsole between EVA foam or polyurethane, especially at the heel's region subjected to higher impact loads.

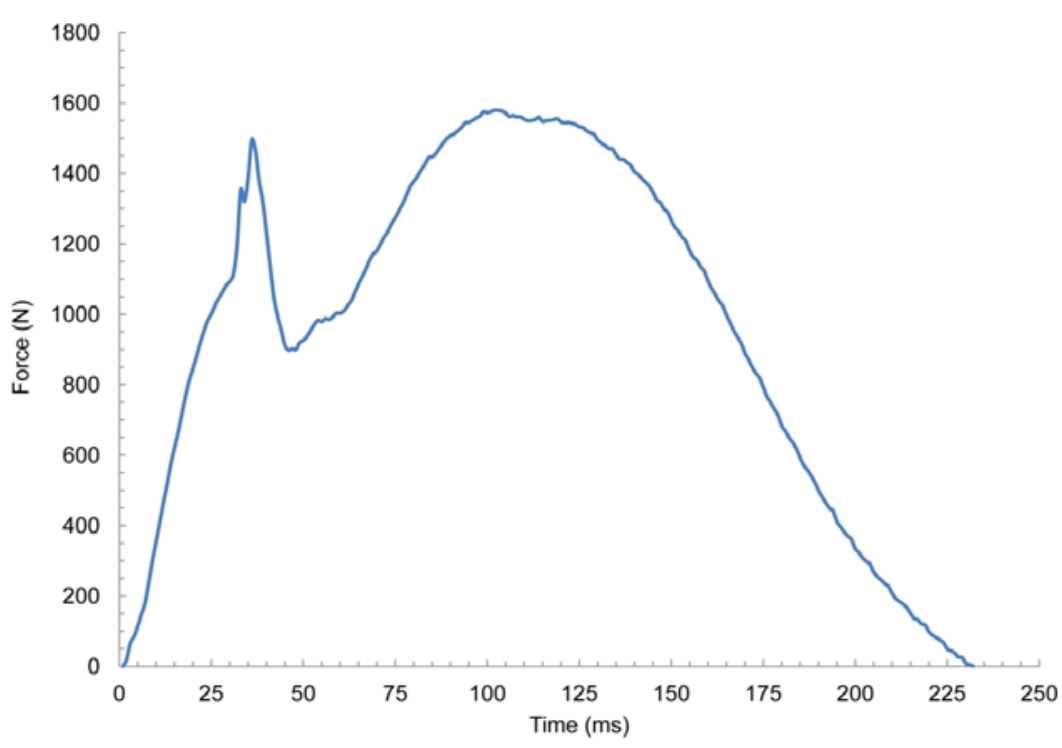

Fig. 1. Vertical ground reaction force during running

In sports products such as skis, rackets, golf clubs, hockey sticks, baseball bats and athletic footwear, composite structures can experience large-deflection bending caused by quasi-static loading and low-velocity impacts during their service. For instance, during running, a sports shoe acts as a cantilever at heel when struck with ground, and the rest of the sole experiences large-deflection bending; which cannot be replicated in drop-weight testing, where flexure is significantly constrained. Although the behaviour of fabric-reinforced composites subjected to low-velocity impact is widely studied, e.g. in [6-10], among others, the loading is mostly of the drop-weight type. The large-deflection dynamic bending behaviour of sports products can be accurately assessed with impact tests on un-notched samples using pendulum-type hammers, which is rarely investigated. Further, kinematics and biomechanics of running are studied to some extent as in $[4,11,12]$; however, characterisation of composite materials for such applications is a novel area to be dealt with in this manuscript. 
In this paper, the flexural behaviour of woven CFRP laminates in warp, weft and off-axis orientations is studied first under large-deflection quasi-static bending. The experimental tests characterised the stiffness, strength and toughness of CFRP laminates. The CFRP laminates are then tested under large-deflection dynamic bending at various levels of impact energy - up to the material's failure. The tests quantified dynamic strength and energyabsorbing capability of CFRP laminates of different orientations. In the tested laminates, various damage modes such as matrix cracking, fibre breakage, tow-matrix debonding, delamination and fabric fracture were analysed with an X-ray micro-CT technique. Micro-CT can provide a full-field high-resolution 3D representation of internal damage modes and their coupling in composites non-destructively as compared to conventional 2D damage-assessment techniques. This relatively recent technique was also employed in [13-15] to analyse damage behaviour of composites at micrometre scale.

\section{Experimental methods}

\subsection{Materials}

The CFRP composites were prepared from carbon fabrics with areal density of $200 \mathrm{~g} / \mathrm{m}^{2}$ reinforced with TPU matrix. The 2D woven preform consisted of T200 carbon fibres with filament diameter of $7 \mu \mathrm{m}$ and 3k tow size. All configurations were produced in a $2 / 2$ twill symmetric weaving pattern with a similar fibre volume fraction of $45 \%$. These materials were specially developed for sports applications requiring higher energy-absorption capability. Hence, a ductile TPU matrix with a higher volume fraction of $55 \%$ was used. The TPU resin is a tough polymer that provides a better resistance to impact and fatigue, making it suitable for applications demanding shock and energy absorption, especially in sports products. Further, thermoplastic matrices such as TPU, polyphenylene sulphide (PPS), and polyether-ether-ketone (PEEK) are also increasingly employed in composite structures due to their higher fracture toughness resulting in a better resistance to impact damage than thermosetting matrices such as epoxy-based composites [16].

The $1 \mathrm{~mm}$-thick specimens were produced from $0^{\circ} / 90^{\circ}$ prepregs using four fabric layers designated as $\left[0^{\circ}, 90^{\circ}\right]_{2 \mathrm{~s}}$, with $\left[0^{\circ}, 90^{\circ}\right]$ representing a single fabric (ply), where $0^{\circ}$ and $90^{\circ}$ are the warp and weft directions of tows, respectively. In this study, the stacking orders of the form $\left[0^{\circ}, 90^{\circ}\right]_{2 \mathrm{~s}}$ and $\left[90^{\circ}, 0^{\circ}\right]_{2 \mathrm{~s}}$ are designated as warp and weft specimens, respectively, also known as specially orthotropic (on-axis) laminates as the plies' orientations coincide with the global orientations in the laminate/structure. Another type of a generally orthotropic (angle ply) laminate, where the plies' orientations are at an angle to the laminate orientation, in the form of $\left[+45^{\circ} /-45^{\circ}\right]_{2 \mathrm{~s}}$ is designated as off-axis specimen. It was also observed from the micro-CT of the specimens that the ends and picks count was 5.2 and 5.14 per cm, respectively. Due to this minor difference, the number of tows in the warp and weft specimens along their longitudinal plane was 13 and 12.85, respectively, based on $25 \mathrm{~mm}$ width of the specimens tested. Detailed parameters of the twill woven CFRP composites are given in the authors' work [15, 17].

In this paper, three types of woven CFRP specimens designated as warp, weft and off-axis were first tested under three-point-bending conditions. In the quasi-static bending tests, five flat rectangular specimens of dimensions $80 \mathrm{~mm}$ (length) $\times 25 \mathrm{~mm}$ (width) $\times 1 \mathrm{~mm}$ (thick) were used for each orientation. However, for dynamic bending tests, un-notched rectangular specimens of $40 \mathrm{~mm} \times 25 \mathrm{~mm} \times 1 \mathrm{~mm}$ were employed for each of three orientations. In these tests, first five specimens for each orientation were used; however, after confirming repeatability of the obtained test results, two specimens per test were found to be sufficient for obtaining reliable results. 


\subsection{Quasi-static bending tests}

The quasi-static bending tests were performed at indenter speed of $100 \mathrm{~mm} / \mathrm{min}$ (strain rate $0.0417 \mathrm{~s}^{-1}$ ) according to ASTM D790 standard using the Instron 5569 machine. A loading span between the supports was kept at 40 $\mathrm{mm}$ in all the three-point bending tests; the tests were performed in the displacement-control regime. The obtained bending stress-strain diagrams for each orientation of CFRP laminates are shown in Fig. 2. In both types of on-axis specimens, flexural tests of warp and weft laminates demonstrated a quasi-brittle behaviour. The reason for this material behaviour is that in on-axis laminates, the applied load is carried by the fibres, which are strong but brittle. Thus, the stress-strain curves are almost linear up to the specimen's catastrophic fracture, represented by an abrupt drop of the stress level in Fig. 2. The maximum stress of $990 \mathrm{MPa}$ in the warp specimen corresponded to a flexural load of $422 \mathrm{~N}$, which is still less than the maximum load-bearing ability of about $1500 \mathrm{~N}$ of a human body during running (Fig. 1), thus causing no fatigue/injuries to human body. As presented in Table 1, the flexural tests resulted in slightly different elastic moduli and flexural strengths for both warp and weft specimens because of the little difference in the ends/pick count of the fabric structure. Stiffness reduction due to internal damage occurred in wrap specimens at about $90 \%$ of the ultimate load, whereas the weft laminates exhibited no stiffness reduction before ultimate fracture. As described in Section 2.1, the number of tows/fibres along the longitudinal plane in warp specimens was a little higher than that of weft specimens; thus, the warp specimens resisted the bending load slightly better than the weft ones. With increasing the load, one or more aligned stiff tows ruptured earlier, at about $90 \%$ of the ultimate load, causing the load drop before catastrophic failure of the warp specimens in the stress-strain diagram shown in Fig. 2. Hence, these specimens gave no warning before their brittle catastrophic failure unlike metals, which is a major drawback to their outstanding mechanical properties, especially in applications demanding energy absorption and yielding. This inherent brittleness of on-axis laminates results in higher safety margins for composites compared to metals. The elastic flexural moduli, ultimate flexural strength, maximum deflection, strain to failure and specific energy absorption, calculated from the mechanical tests of the warp, weft and off-axis specimens, are listed in Table 1. Here, the strains to failure are somewhat higher than those of epoxy-based CFRP laminates due to compliant TPU matrix. Bergmann et al. [18] studied the effect of thermoset as well as thermoplastic matrices such as epoxy and PEEK, respectively, on the mechanical properties and energy-absorption capability of woven fabricreinforced composites subjected to $\pm 45^{\circ}$ off-axis tensile loading. For the same loading conditions, fabric type and laminate stacking, they found that thermoplastic PEEK-based composites resulted in an increase in elastic modulus of $26.5 \%$, tensile strength of $17 \%$ and strain-to-failure of $10.5 \%$ than that of epoxy-based composites. Due to their better mechanical properties, fabric-reinforced composites with thermoplastic matrix such as TPU are employed for sports applications in this study.

Table 1: Mechanical properties and specific energy absorption of CFRP laminates under quasi-static bending

\begin{tabular}{cccccc}
\hline Orientation & $\begin{array}{c}\text { Flexural } \\
\text { modulus } \\
(\mathrm{GPa})\end{array}$ & $\begin{array}{c}\text { Ultimate } \\
\text { flexural strength } \\
(\mathrm{MPa})\end{array}$ & $\begin{array}{c}\text { Maximum } \\
\text { deflection } \\
(\mathrm{mm})\end{array}$ & $\begin{array}{c}\text { Strain to } \\
\text { failure }(\%)\end{array}$ & $\begin{array}{c}\text { Specific energy } \\
\text { absorption } \\
(\mathrm{kJ} / \mathrm{kg})\end{array}$ \\
\hline Warp $\left[0^{\circ}, 90^{\circ}\right]_{2 \mathrm{~s}}$ & $55.0 \pm 1.5$ & $993.0 \pm 25$ & $5.1 \pm 0.3$ & $1.85 \pm 0.07$ & $6.2 \pm 0.4$ \\
Weft $\left[90^{\circ}, 0^{\circ}\right]_{2 \mathrm{~s}}$ & $52.0 \pm 1.4$ & $885.0 \pm 23$ & $4.75 \pm 0.26$ & $1.76 \pm 0.06$ & $5.1 \pm 0.3$ \\
Off-axis $\left[+45^{\circ} / 45^{\circ}\right]_{2 \mathrm{~s}}$ & $16.3 \pm 1.1$ & $478.0 \pm 11$ & $8.75 \pm 0.36$ & $4.5 \pm 0.1$ & $8.5 \pm 0.6$ \\
\hline
\end{tabular}




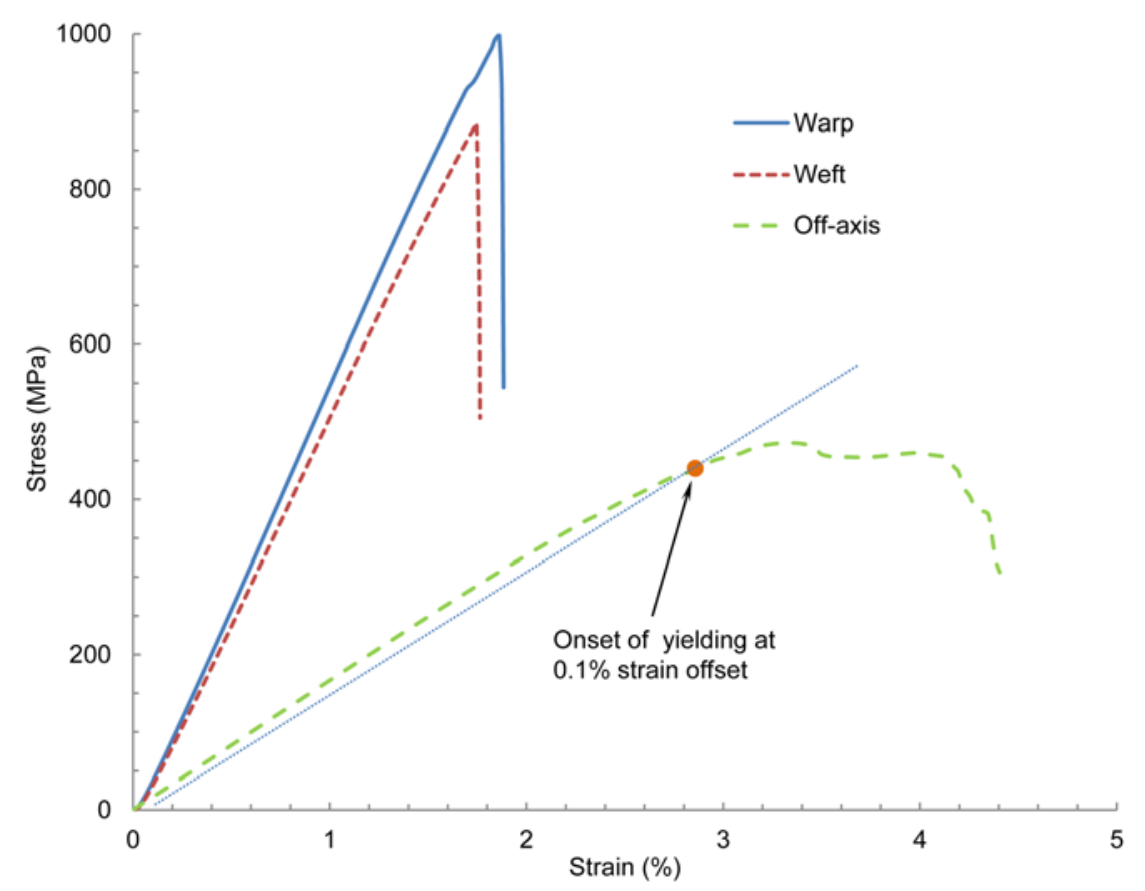

Fig. 2. Stress-strain diagram from quasi-static flexural tests of twill 2/2 CFRP specimens

As shown in Fig. 2, the off-axis specimens demonstrated a large-deformation nonlinear behaviour before their ultimate failure as compared to their on-axis counterparts. This ductile behaviour is due to matrix plasticity as well as cracking and alignment of tows along the loading directions called fibre trellising. The latter is the result of fibres reorientation towards the loading direction, with the angle between warp and weft fibres changing from $90^{\circ}$ with increasing the load level. This behaviour is more pronounced in off-axis specimens tested under uniaxial tensile loads resulting in strains to failure up to $30 \%$ as studied in [19]. Such ductile, or yielding behaviour of composites is more desirable for energy-absorption purposes and is termed pseudo-ductility in recent research works such as [20]. Recently, various approaches, such as partially discontinuous ply architecture [21], hybrid laminates with higher ductile fibres, intermingled cuts, single-polymer composites [22] and offaxis/angle-ply laminates have been proposed to improve the yielding behaviour of composites. In this work, this pseudo-ductility in angle-ply laminates is studied for sports applications for the first time. Thanks to such behaviour, the off-axis laminates are still capable to bear a load after the damage initiated at the yield point (Fig. 2). Here, the yield point refers to the knee where the stress-strain curve deviates from the initial elastic line and does not necessarily indicate the presence of plastic deformation as observed in metals. Further, the off-axis specimens exhibited higher levels of strain to failure - 4.5\% - than the on-axis specimens. The specific energy absorption, calculated from the area under the stress-strain curve divided by the material density $\left(1450 \mathrm{~kg} / \mathrm{m}^{3}\right)$, was $8.5 \mathrm{~kJ} / \mathrm{kg}$, which is some $60 \%$ higher than that of the on-axis specimens (Table 1). However, the increase in energy-absorption capability is accompanied by a reduction in stiffness and strength properties of the tested offaxis specimens. These properties can be improved by selecting ply angles in the range from $20^{\circ}$ to $30^{\circ}$ depending on various applications. Still, it is evident that off-axis laminates are capable to plastically deform and absorb energy like metals before their ultimate failure. Further, it was reported in [18] that thermoplastic PEEKbased composites demonstrated in 10\% higher specific energy absorption than epoxy-based composites tested under similar conditions.

\subsection{Dynamic bending tests}

\subsubsection{Experimental procedure}


Dynamic tests were performed to characterise the bending behaviour of composite laminates under low-velocity impact regimes characteristic of the sports products in their service. Dynamic bending tests in an impact energy range from $0.1 \mathrm{~J}$ to $1.2 \mathrm{~J}$ were carried out according to the ASTM D4812 standard using a pendulum-type CEAST Resil impactor as shown in Fig. 3. In these tests, the bottom of the specimen was held in a clamping vice, whereas its upper part (30 mm) was struck by the impactor with specified impact energy, resulting in dynamic large-deflection flexure. With the same mass of impactor, the impact energy levels were varied by changing the initial angle of the hammer. A piezoelectric force sensor was fixed to the hammer's striker to measure the impact load. The data acquisition was achieved using DAS 8000 system at $227 \mathrm{kHz}$ frequency. The force-time history of the dynamic event was recorded. The rest of the dynamic test parameters can be calculated using the equations given below, with the assumption of perfectly rigid impactor. The hammer's initial velocity at the moment just before the contact takes place can be determined from the potential energy using the following equation:

$$
v_{i}=\sqrt{2 g h_{d}},
$$

where $v_{i}$ is the velocity at impact, $h_{d}$ is the drop height, and $g$ is the acceleration of gravity. By integrating the force history, the hammer's velocity $v(t)$, deflection $\delta(t)$, and absorbed energy $E_{a}$ can be determined, respectively, using the following equations:

$$
\begin{aligned}
& v(t)=v_{i}-\frac{1}{m} \int_{0}^{t} F(t) d t, \\
& \delta(t)=\int_{0}^{t} v(t) d t \\
& E_{a}=\frac{m}{2}\left(v_{i}^{2}-v^{2}\right) .
\end{aligned}
$$

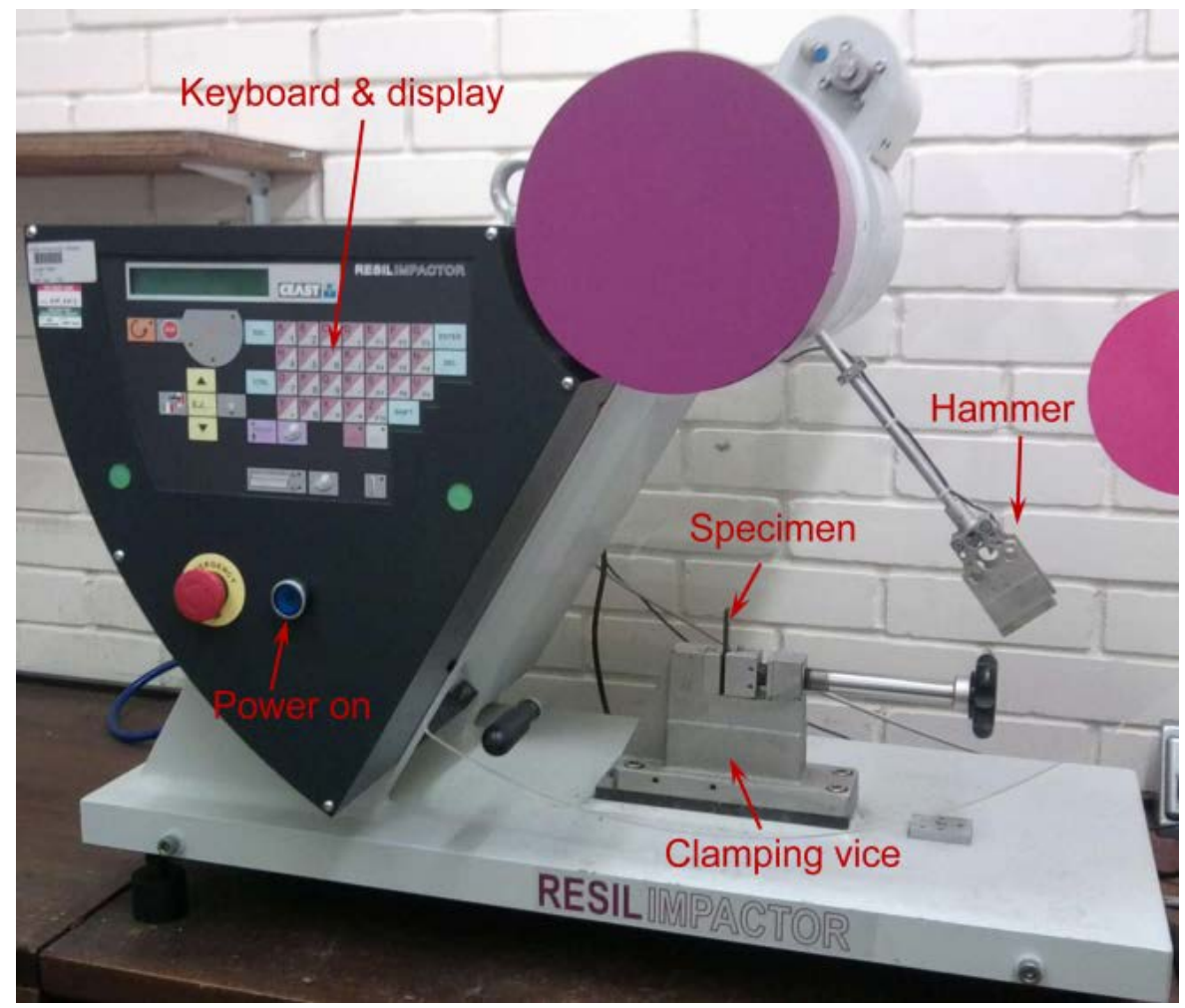

Fig. 3. Resil test set-up for impact bending

\subsubsection{Results and discussion}


The transient bending response of CFRP laminates in the warp, weft and off-axis orientations was evaluated in impact tests at energy levels ranging from $0.1 \mathrm{~J}-1.2 \mathrm{~J}$. The dynamic response of the material includes the load, deflection, and energy as functions of time. Diagrams of evolution of load-time, load-deflection and energy-time graphs were plotted for representative samples at each energy level. Key impact parameters such as peak load, time to peak load and deflection at peak load were evaluated by the data acquisition system, and are elaborated in this section.

\section{Force-time response}

The impact force-time responses of CFRP warp, weft and off-axis specimens tested at different energy levels are illustrated in Fig. 4. It can be observed that both the slope and maximum peak force of the curves increased with impact energy. At lower impact energies, the force increased linearly with time at the beginning of impact, indicating the behaviour of undamaged specimen. After the maximum load peaks, the hammer bounced back and the load reduced to zero. The loading and unloading portions of the curves for both the warp and weft specimens up to $0.4 \mathrm{~J}$ and off-axis specimens up to $0.3 \mathrm{~J}$ had a nearly symmetric parabolic shape; indicating the occurrence of little damage in the form of a dent or matrix cracking at the impact point. In these impact tests, the energy was rather stored elastically in the specimens like a spring. As the impact energy was increased to $0.5 \mathrm{~J}$ and $0.4 \mathrm{~J}$ for warp and weft specimens, respectively, oscillations in the force-time plots can be observed before the load peaks. These fluctuations associated with load drops are designated as $\mathrm{F}_{\mathrm{di}}$ in Figs. $4 \mathrm{a}$ and b, representing the onset of damage such as delamination and matrix cracking linked with reduction in the laminate stiffness [23, 24]. The curves became non-symmetric with regard to their peaks at $0.5 \mathrm{~J}$ as can be seen in Figs. 4a and b. In these tests, at $0.6 \mathrm{~J}$ impact energy, fabric fracture occurred in both types of specimens denoted by an abrupt drop in impact force indicating a loss of contact between the hammer and laminate. This was caused by brittle fracture of the fabric in tension in the front face of the specimen as a result of bending. The force did not reduce to zero in the warp specimens, as the back-face plies under compression were not fractured, causing a residual load of about 20 $\mathrm{N}$. However, in the weft specimen, the load dropped to zero representing the laminate's complete fracture.

In the off-axis specimens, as the impact energy increased up to $0.4 \mathrm{~J}$, the loading and unloading parts showed nonlinear behaviour instead of oscillations, demonstrating that plasticity of the laminates resulted in a lower level of damage in them than in on-axis specimens. The specimens impacted at energies between $0.8 \mathrm{~J}-1.1 \mathrm{~J}$ also showed a permanent bending-like deflection after tests (Fig. 4c), which might be due to pseudo-plasticity of the off-axis laminates. The plasticization of matrix in the resin-rich regions also played an important role by leading to local permanent deformations due to ductility of the TPU matrix, apart from fibre trellising. At higher energy levels, the specimens exhibited more pronounced yielding, implying the onset of plastic deformation indicated by the plateau at the top of the curves (Fig. 4c). The specimens also exhibited a snap-back during the rebound, shown by the depths and kinks in Fig. 4c. Unlike the on-axis specimens, the peak loads remained almost the same, with an appreciable increase in the deformation of the off-axis specimens at higher impact energies. The off-axis specimens failed at higher impact energy of $1.2 \mathrm{~J}$ than the on-axis specimens, but the failure was not sudden and catastrophic, giving a warning in the form of load reduction (Fig. 4c). Here, a residual load remained after failure, and the specimens were still intact as can be seen from micro-CT images in Fig. 12.

In both types of warp and weft specimens, the impact force increased with the impact energy, however, with a little effect on the contact durations (Fig. 4). The reason is that higher impact velocities induced larger deformations and, therefore, larger impact forces. 

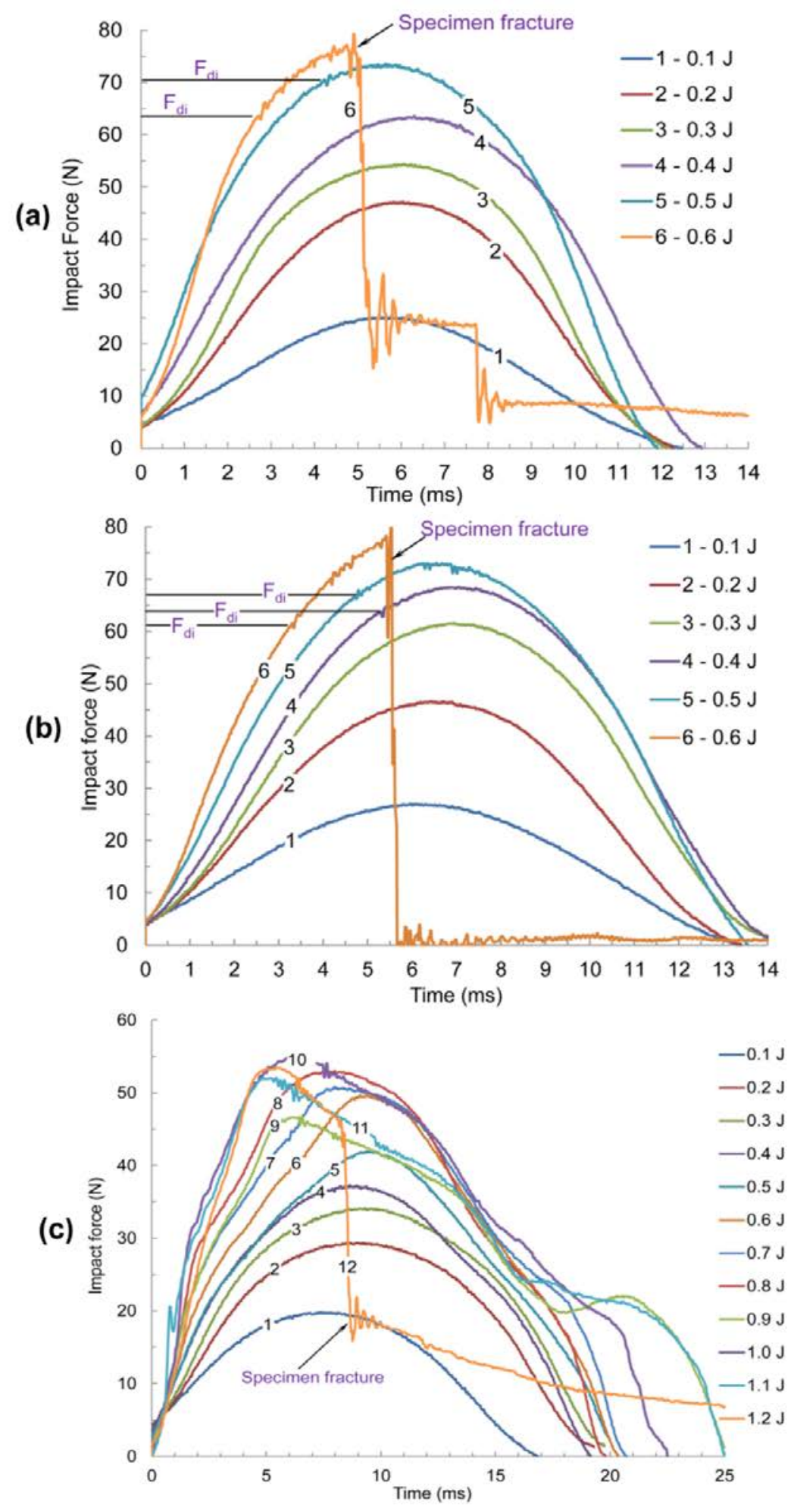

Fig. 4. Force-time responses of CFRP warp (a), weft (b) and off-axis (c) laminates at various impact energies

Further, the contact durations remained almost the same with increase in the impact velocity for on-axis specimens. Such a response indicates that the material's behaviour is strain-rate-independent under dynamic loading in fibre-dominated modes as was also observed in [25]. However, the off-axis specimens exhibited a rate-dependent behaviour due to their matrix-dominated response, as the contact duration increased with the impact energy (Fig. 4c). The peak loads for the on-axis specimens were higher than those of the off-axis ones at 
the corresponding energy levels due to the higher material's stiffness (see Table 1). The latter also resulted in lower contact duration for the on-axis specimens than that for the off-axis specimens at the respective impact energy levels. However, the off-axis specimens did not exhibit a catastrophic brittle fracture like the on-axis specimens but rather demonstrated behaviour similar to yielding at higher impact energies (Fig. 4c). This implies that although off-axis laminates are less strong, they can tolerate higher impact energy before their failure. In experiments, the specimens failed at low energy levels because of lower flexural rigidity due to their boundary conditions and geometric parameters.

\section{Force-deflection response}

The force-deflection (F-d) responses for the warp, weft and off-axis configurations of CFRP samples at different impact energy levels are given in Fig. 5. Actually, all the curves started from the origin but due to higher Hertzian stiffness between the hammer and the specimen at the start, the load seemed to start from non-zero values. In cases without impact damage, a peak load relates to the maximum resistance provided by the specimen as an indication of its flexural stiffness [24]. The slope of F-d curves indicates the contact stiffness, while the area under the curve is the energy absorbed, which is increased with impact energy. It is worth mentioning that a membrane stiffening effect also occurred in thin laminates as the maximum deflection was several times greater than the specimen's thickness.

In the materials under study, apart from the pseudo-ductility in angle-ply laminates, the TPU matrix was highly ductile and, thus, absorbed more energy without inducing any appreciable damage. Here, again, there is a significant difference in the behaviour of the on-axis specimens as compared to the off-axis specimens. For the on-axis specimens, stiffness (the slope of the load-deflection curve) showed a significant linear increase with the impact energy, whereas, for the off-axis specimens only a small increase in stiffness was observed, as was also the case in quasi-static tests. The increase in stiffness can be associated with higher values of the Young's moduli of the on-axis laminates than that of the off-axis laminates (Table 1). Due to lower stiffness, the maximum deflection of the off-axis specimens was almost double than that of the on-axis specimens at the respective impact energy levels resulting in higher strains-to-failure magnitudes. From the F-d curves in Figs. 5a and b, stiffness of the on-axis specimens was $5.8 \mathrm{~N} / \mathrm{mm}, 8.5 \mathrm{~N} / \mathrm{mm}, 9.1 \mathrm{~N} / \mathrm{mm}, 9.3 \mathrm{~N} / \mathrm{mm}, 11.6 \mathrm{~N} / \mathrm{mm}$ and 12.6 $\mathrm{N} / \mathrm{mm}$ for impact energy levels of $0.1 \mathrm{~J}, 0.2 \mathrm{~J}, 0.3 \mathrm{~J}, 0.4 \mathrm{~J}, 0.5 \mathrm{~J}$ and $0.6 \mathrm{~J}$, respectively. However, the quasi-static flexural tests of on-axis specimens resulted in a higher value of about $85.8 \mathrm{~N} / \mathrm{mm}$. Similarly for off-axis laminates, the stiffness form F-d curves (Fig. 5c) was about $2.6 \mathrm{~N} / \mathrm{mm}$ (almost the same for all energy levels) as compared to its quasi-static value of $35 \mathrm{~N} / \mathrm{mm}$. This discrepancy was due to the boundary conditions of specimens in both types of testing. In quasi-static tests, the specimen acted as a simply supported beam whereas in dynamic ones, the specimen was like a cantilever beam. It is evident from the basic beam theory that the stiffness of simply supported beam is almost 16 times higher than that of a cantilever one; a mismatch of this order is represented when the stiffness of $0.1 \mathrm{~J} \mathrm{~F}$-d curves is compared with quasi-static one for both the on-axis and off-axis specimens.

The initiation and progress of damage were evident by oscillations in the load at higher energy levels for the onaxis specimens, whereas the off-axis specimens exhibited pronounced nonlinearity due to matrix plasticity and fibre trellising (pseudo-ductility). The latter also resulted in larger areas under the F-d curves for off-axis specimens indicating their higher energy absorption capabilities before failure. Further, it was also observed that the off-axis laminates required higher impact energies for specified damage and failure. 

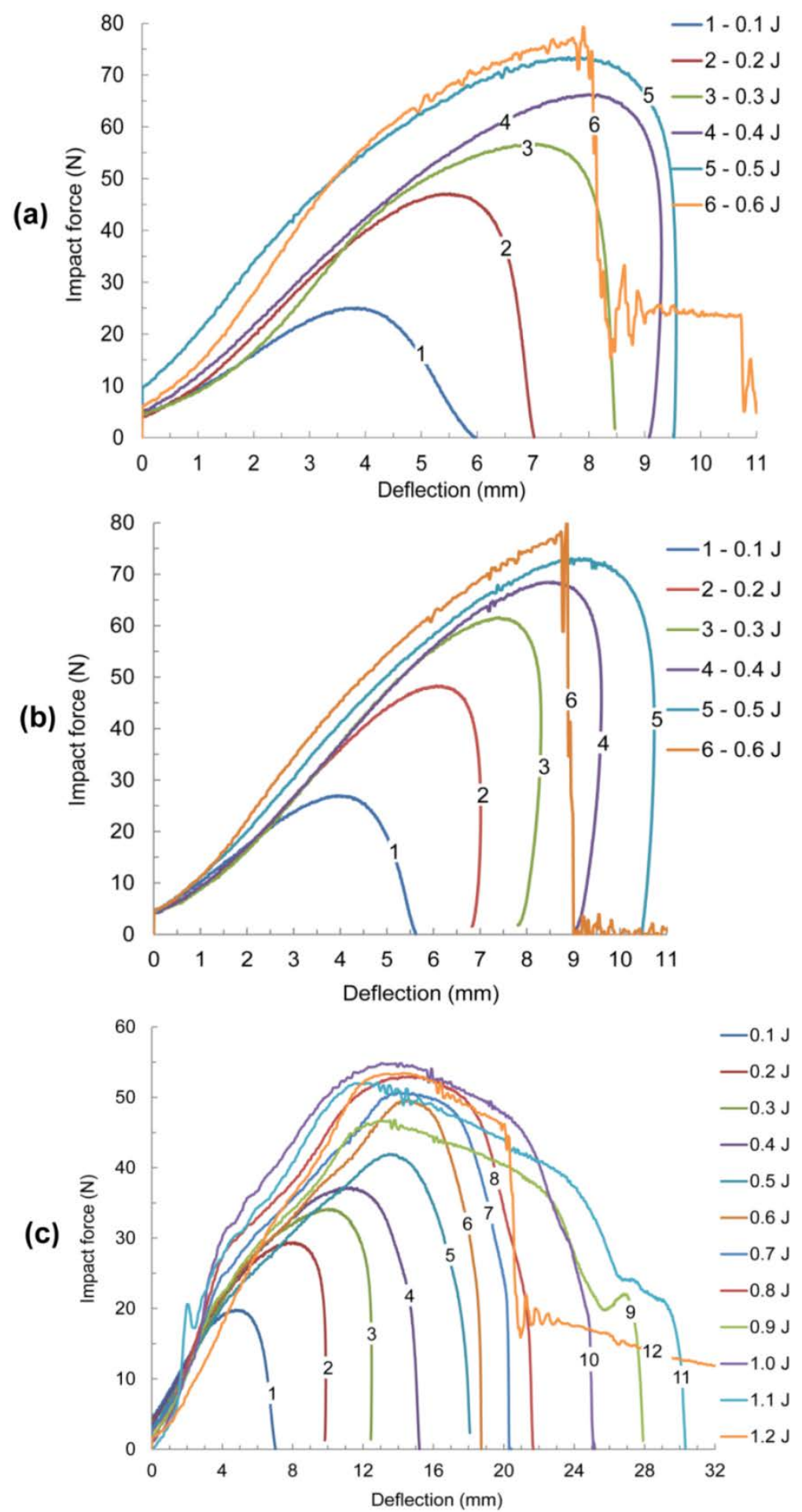

Fig. 5. Force-deflection responses of CFRP warp (a), weft (b) and off-axis (c) laminates at various impact energies

Vieille et al. [16] conducted a comparative study on the impact behavior of woven carbon fiber-reinforced composites with thermoplastic matrices such as PEEK and PPS as well as thermosetting matrix such as epoxy composites. They observed that thermoplastic-matrix composites demonstrated higher damage tolerance and energy absorption capability than epoxy-based ones. It was found that the latter displayed larger delaminated areas, reaching values about twice as high for low impact energies; thus, tougher thermoplastic matrices resulted in better impact performance. 


\section{Energy-time response}

Variation of energy with time for the warp, weft and off-axis CFRP specimens at different impact energies is shown in Fig. 6. As the impactor hit the specimen, the latter started absorbing the impactor's kinetic energy. The energy increased during loading until a maximum value and then decreased during a rebound and ultimately remained horizontal. This constant value gives the total energy absorbed by the specimen at the end of an impact event. Energy absorption in composites is mainly through elastic strain energy, plastic deformation and formation of various damage mechanisms [26].
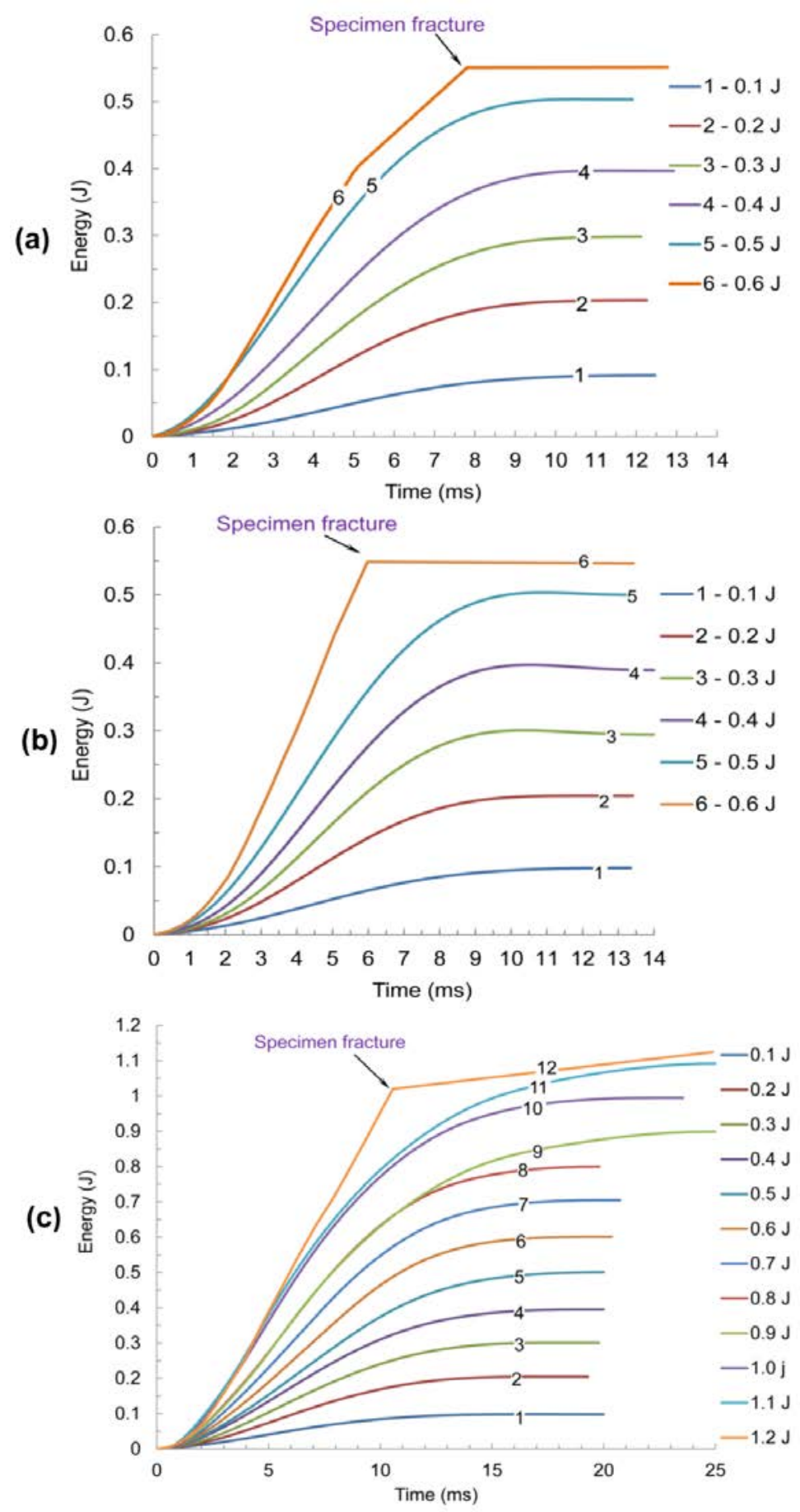

Fig. 6. Energy-time responses of CFRP warp (a), weft (b) and off-axis (c) laminates at various impact energies 
As studied in Section 2.2, the on-axis composite laminates exhibited quasi-brittle behaviour; thus, there was no associated plastic deformation. In these specimens, impact energy was absorbed through elastic deformation as well as development of various damage modes. However, the off-axis laminates exhibited a metal-like ductile behaviour before their failure and, hence, absorbed larger amounts of energy through plasticity, making them a preferable material for energy-absorption requirements as in sports products. Further, as shown in Fig. 6, the energy absorbed by the specimens increased with the impact energy since higher impact energy resulted in large deformation and damage to the specimens. In the on-axis specimens, the energy decreased slightly after reaching its maximum value representing little rebounding of the hammer. However, for the off-axis specimens, the energy remained constant after reaching its maximum value, showing no rebound. Still, in the tests of all types of specimens, the hammer rebounded at low energies. This may be due to the fact that the complaint TPU matrix absorbed the energy in the on-axis laminates augmented by plasticity in the off-axis specimens. At impact energy of $0.6 \mathrm{~J}$, the absorbed energy reached a value of $0.46 \mathrm{~J}$ at $5.5 \mathrm{~ms}$ and then gradually increased till $0.55 \mathrm{~J}$ at $8 \mathrm{~ms}$ and remained constant after fracture of the warp tests. In the weft tests, the absorbed energy reached a value of $0.55 \mathrm{~J}$ at $5.5 \mathrm{~ms}$ and then became constant. In the off-axis tests, this happened at $11 \mathrm{~ms}$, with absorbed energy of $1.05 \mathrm{~J}$. The stabilized energy levels indicated that the specimens fractured and the impactor lost contact with them. Similar energy profiles were also obtained for thin glass-fibre woven laminates under impact loads studied in [27].

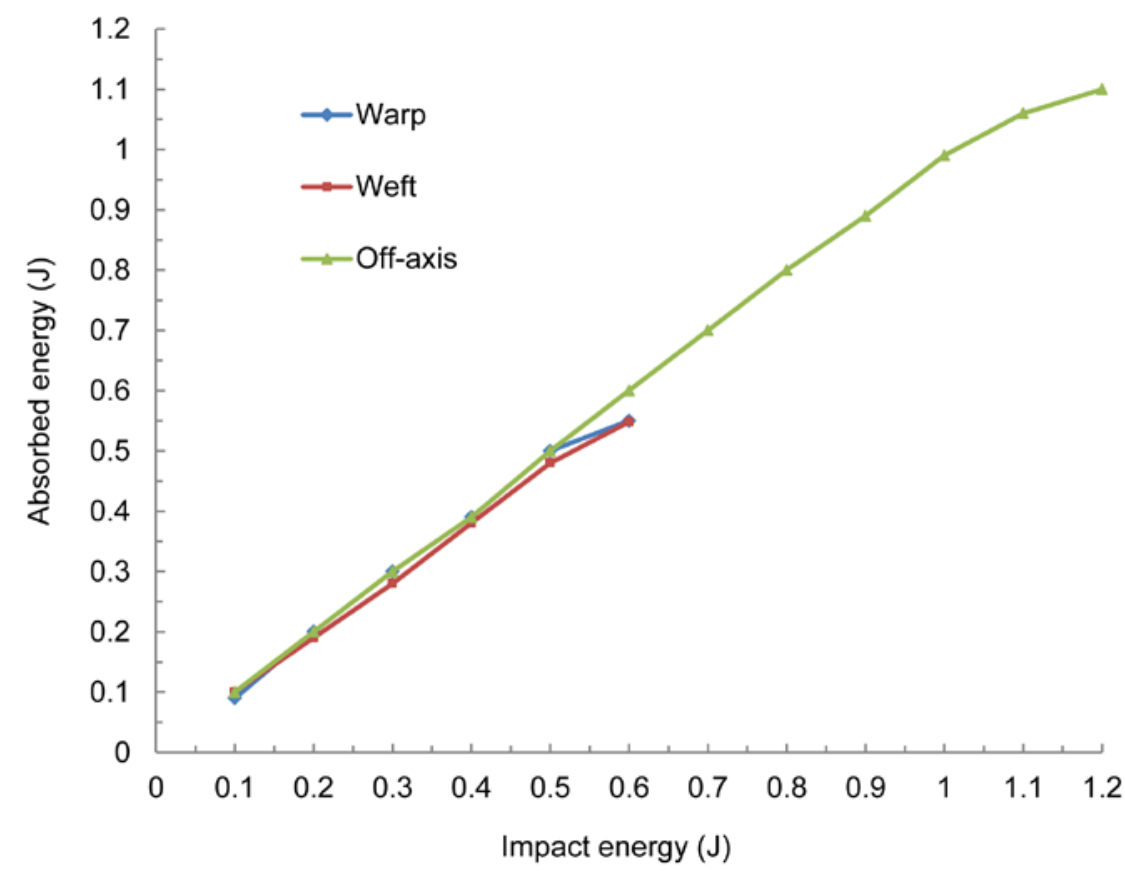

Fig. 7. Variation of absorbed energy with impact energy of CFRP warp, weft and off-axis specimens

Variation of the absorbed energy with impact energy, i.e. energy profile diagram is plotted for the warp, weft and off-axis specimens in Fig. 7. Here, the points below the equal energy line (a bisector) show the remaining energy retained by the impactor and used to rebound it from the specimen at the end of impact [27]. Here, too, the rebounding phenomena were exhibited more by the on-axis specimens than the off-axis. The energy profile diagram also showed that the off-axis specimens absorbed more energy without any rebound represented by an 
almost straight line than the on-axis specimens. At impact energy of $0.6 \mathrm{~J}$, both types of warp and weft specimens showed fracture after absorbing lower amounts of energy. This also implied that the hammer did not result in further damage in the laminates even if the impact energy increased. However, the off-axis laminates showed greater energy-absorbing capability up to impact energy of $1.2 \mathrm{~J}$ prior to their ultimate fracture.

\section{Micro-computed-tomography analysis of damage}

Micro computed tomography was used to analyse a 3D nature of various damage modes and their location in the impacted CFRP specimens at microstructural level. The gathered information can be used for damage-tolerant design as well as simulation of actual damage modes in composites employed in sports products. In this work, an XT H 225 X-ray scanner was employed for 3D scanning. Its X-ray source is a sealed tube operating at voltage range of $25-225 \mathrm{kV}$ with a $3 \mu \mathrm{m}$ spot size. An object manipulator positioned the sample to a specific region of interest (ROI) for acquisition of tomographic data. Detailed information of internal damage in the specimens needs high-resolution scanning. Thus, increased resolution results in reduction of the field of view (FOV) of the sample. However, samples must be positioned within the FOV to acquire the data of the ROI; therefore, a tradeoff is needed. In this work, the reconstruction of tomographic data was performed using CT-Pro software, and the analysis of the resulting 3D volumes was implemented with the VG Studio Max 2.2 software to partition and highlight the ROI. Since the dynamic behaviour of warp and weft specimens was almost similar, only damage characterisation of the warp specimens at two energy levels along with off-axis specimens is presented.

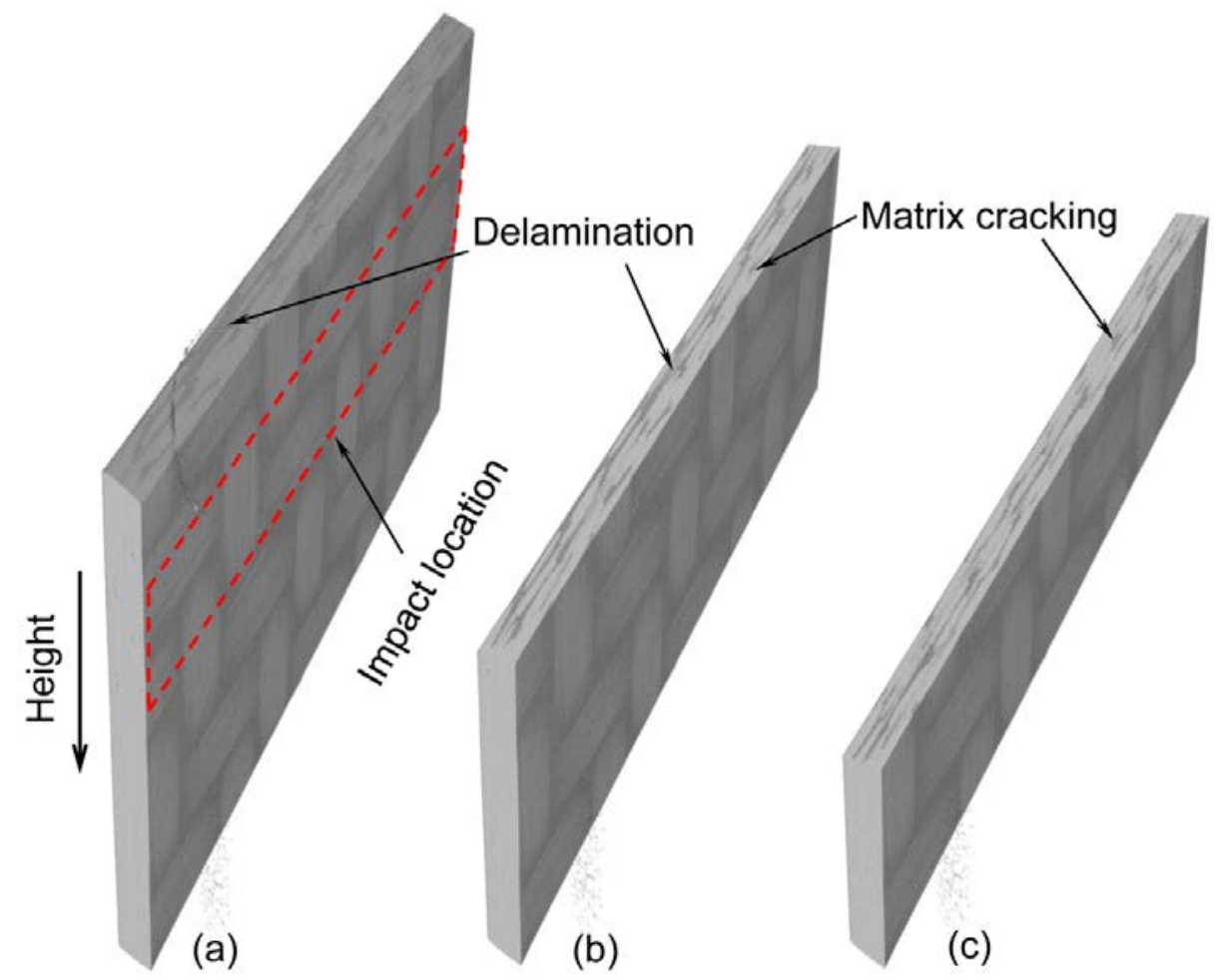

Fig. 8. Tomographic 3D images of warp specimen at impact location along the height of sample: (a) full; (b) half; (c) one-third of hight

\subsection{Analysis of damaged warp specimen}

A sample of $20.6 \mathrm{~mm}$ length, $10.2 \mathrm{~mm}$ width and $1 \mathrm{~mm}$ thickness from the impact location of the damaged 
CFRP warp specimen impacted at $0.5 \mathrm{~J}$ was prepared for 3D scanning. The sample was exposed to X-rays generated at $75 \mathrm{kV}$ and $80 \mu \mathrm{A}$. Radiographic images were obtained from 3600 rotation views over $360^{\circ}$ of rotation $\left(0.1^{\circ}\right.$ rotation step) during $3 \mathrm{D}$ reconstruction. The tomographs thus reconstructed, had a resolution of $14.7 \mu \mathrm{m}$ for the impact specimen, and are illustrated in Fig. 8. These tomographs demonstrate cracks in the TPU matrix and delamination at the impact point along the sample's height. Matrix cracks developed in weak resin dominated regions around the yarns and initiated inter-ply delamination. Micro-CT analysis showed that matrix cracking and interlaminar delamination were the significant damage modes underneath the impactor contact zone.

\subsection{Analysis of fractured warp specimen}

The CFRP warp specimen fractured at $0.6 \mathrm{~J}$ impact energy was also scanned employing micro-CT at the impact as well as fracture (bending) location. Here, to obtain high-resolution images, two small samples, one with dimensions of $10.14 \mathrm{~mm} \times 6.0 \mathrm{~mm} \times 1.0 \mathrm{~mm}(\mathrm{~W} \times \mathrm{H} \times \mathrm{T})$ from the impact region, and the second with dimensions of $8.35 \mathrm{~mm} \times 6.10 \mathrm{~mm}$ x $1.0 \mathrm{~mm}$ from the fractured region were prepared. The radiographic data was generated at $80 \mathrm{kV}$ and $85 \mu \mathrm{A}$ of energy levels of $\mathrm{X}$-rays. Here, too, for 3D reconstruction, radiographs were acquired with rotation step of $0.1^{\circ}$. The obtained tomograms had resolution of $6.7 \mu \mathrm{m}$ and $6.1 \mu \mathrm{m}$ for the impact and fractured specimens, respectively.

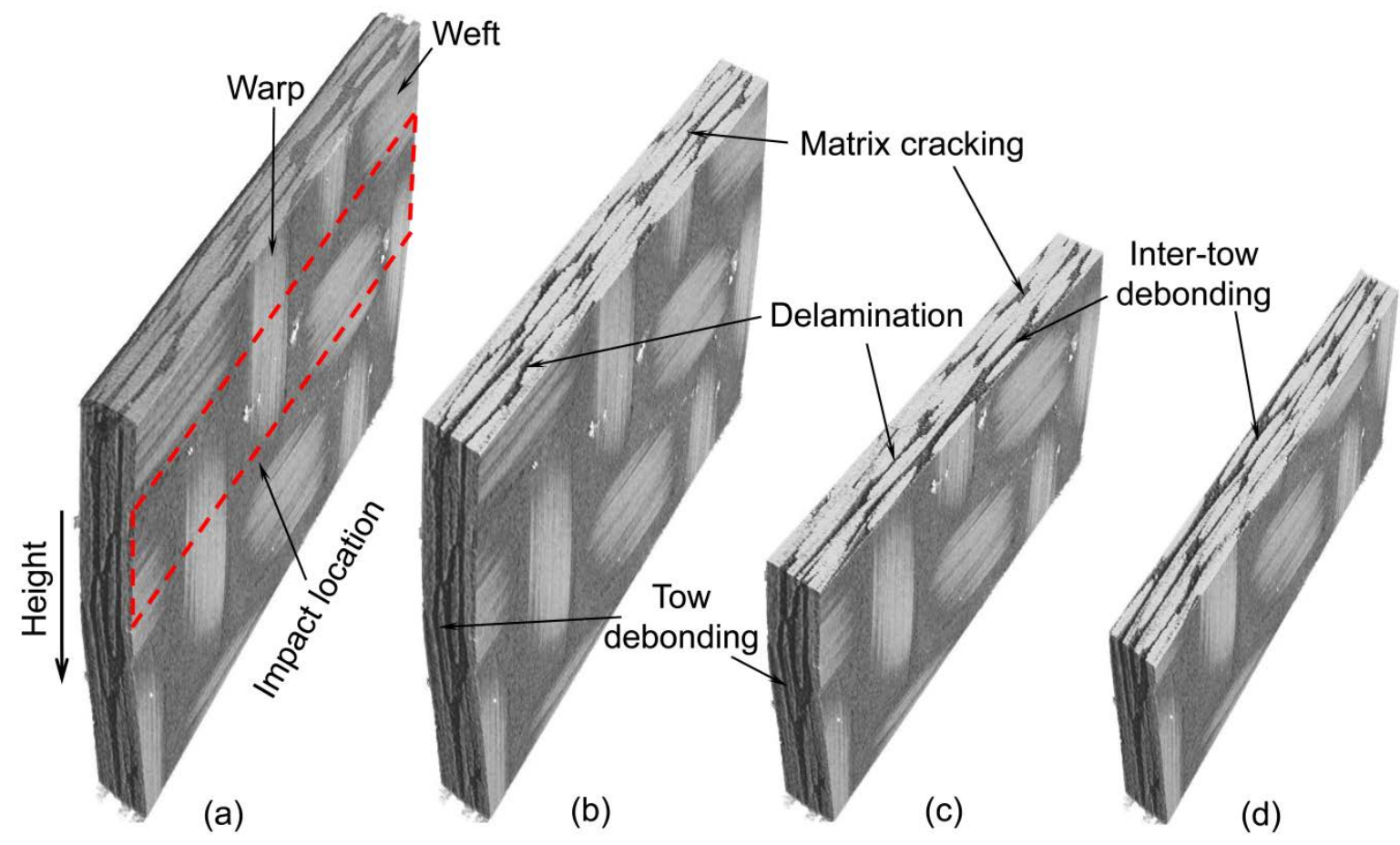

Fig. 9. Tomographic 3D images of warp specimen at impact location along the height of sample: (a) full; (b) three-quarter (1 mm above impact centre line) (c) half (at impact centre); (d) one-quarter (below impact centre line) of height

The tomographs of the fractured specimen at the impact location are shown in Fig. 9. Matrix cracking, delamination and tow debonding at the hammer's impact location along the specimen’s height are evident. It can also be observed that the inter-tow cracks propagated into the resin pockets. At the impact location (Fig. 9c), the interface on the impact side (specimen's front) was more damaged than the back. Dents in the tows below the striker are also visible. All the resin-rich interfaces underwent inter-ply delamination below the impactor. The 
tomographs of the CFRP specimen at the fractured location presented in Fig. 10 demonstrate interlaminar and intralaminar damage mechanisms at various positions along the sample's width. It is evident that the specimen exhibited progressively matrix cracking and then delaminations and tow debondings until its ultimate fracture. Matrix cracking was dominant in the resin-rich regions surrounding the tows. Interlaminar delamination, i.e. separation between adjacent fabric plies, and intralaminar delamination such as tow debonding, which is separation between tows within a single ply, can also be observed. In the fibre-rich regions, the apparent damage mode was debonding at the tow/matrix interface. The analysis of internal structure showed that at the time of fabric fracture, triggered by tensile fibre failure, almost every ply was delaminated. This delamination is more pronounced in Figs. 10a and c than in 10b and d. The reason is that warp tows, which are aligned along the specimen's axis, bear a higher load than transverse weft tows in bending of the specimen under impact. All the tomographs demonstrate that matrix cracking, delamination and tow debonding were the significant damage modes at the specimen's impact location, whereas at the bending location, apart from these modes, fabric fracture was also observed.

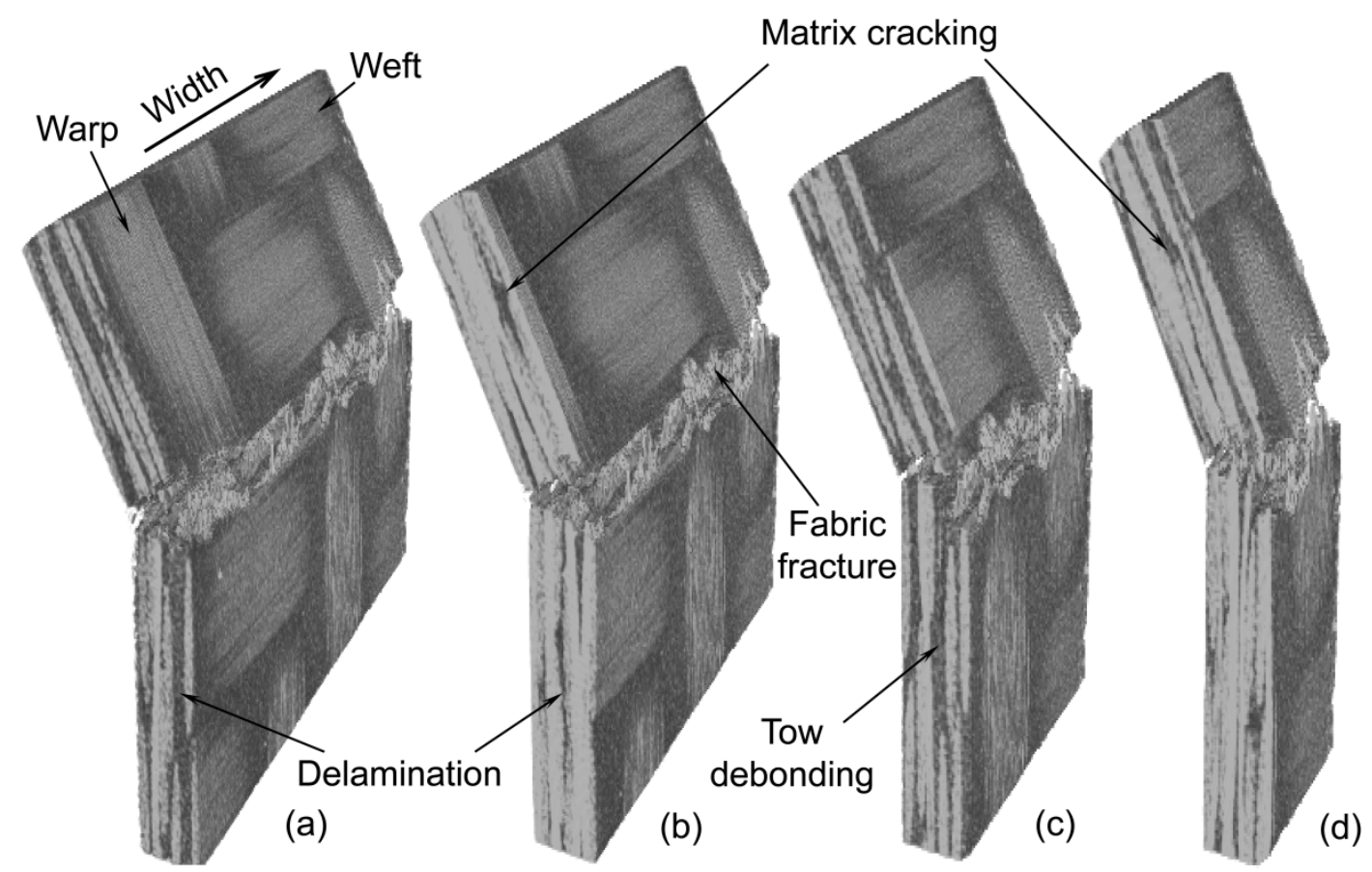

Fig. 10. Tomographic 3D images of warp specimen at bending (fracture) location along the height of sample: (a) Full; (b) three-quarter; (c) half; (d) one-quarter of width

In this damage analysis, both large- and small-size samples from the impact region were scanned in an attempt to investigate various damage modes at different resolutions. At lower resolution of $14.7 \mu \mathrm{m}$, only some major damage modes in the form of matrix cracking and delamination were observed (Fig. 8). Reducing the sample size by almost half resulted in images with $6.7 \mu \mathrm{m}$ resolution that showed tow debonding apart from the matrix cracking and delamination (Fig. 9). Hence, it is evident that increasing the sample size results in loss of realistic damage information, while reducing the sample size limits the analysis to a localized region. This limits the use of the micro-CT technique, preventing a study of a complete damage picture in a full-scale specimen. Therefore, here, too, a trade-off is needed between the sample size and the requisite damage information. However, microCT is still surpassing all other damage characterisation techniques in that it provides complete 3D internal information for the materials. 


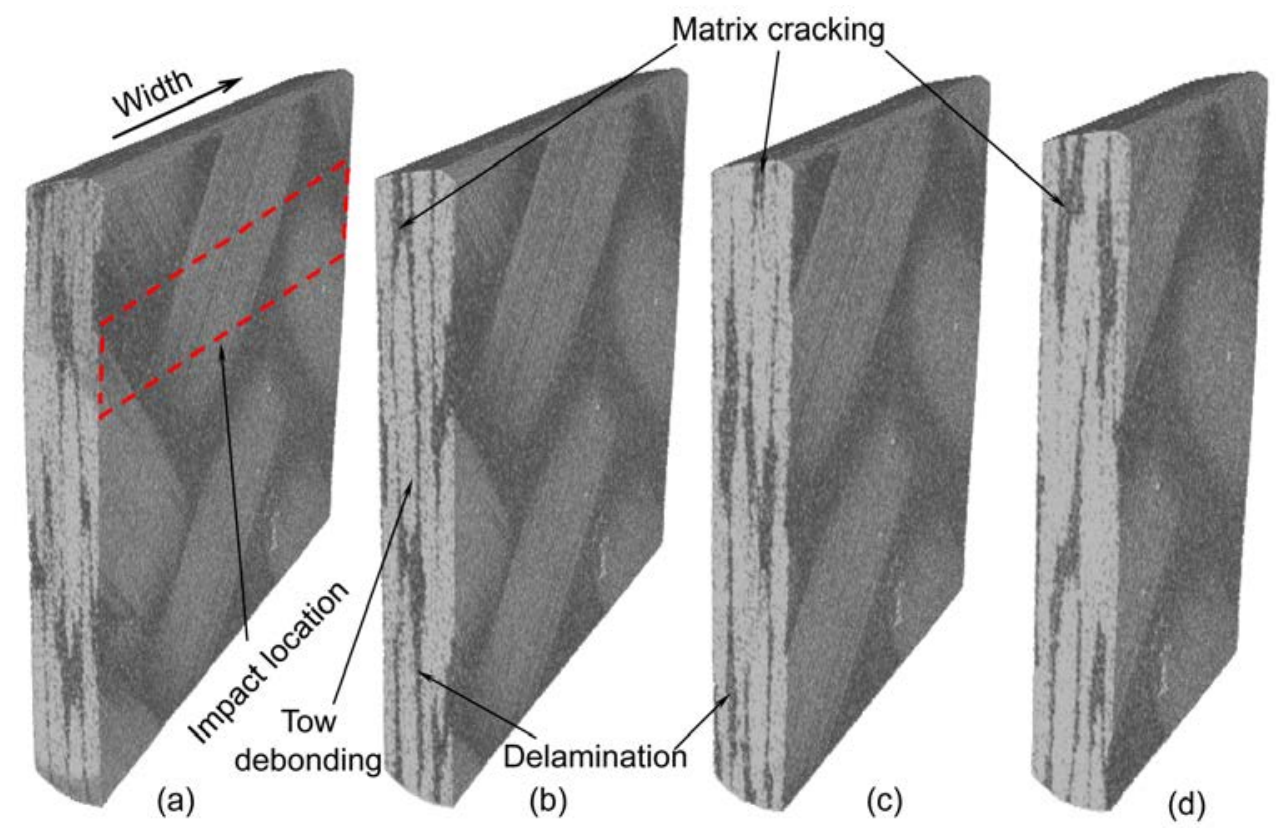

Fig. 11. Tomographic 3D images of off-axis CFRP specimen at impact location along the width of sample: (a) full; (b) three-quarter; (c) half; (d) one-quarter of width

\subsection{Analysis of fractured off-axis specimen}

Here, two samples of the off-axis CFRP laminates, one with dimensions of $6.42 \mathrm{~mm}$ x $6.0 \mathrm{~mm}$ x $1.0 \mathrm{~mm}$ from the impact region, and second with dimensions of $21.4 \mathrm{~mm} \times 14.1 \mathrm{~mm} \times 1.0 \mathrm{~mm}$ from the bending/fractured region were prepared. The tomographs with resolution of $4.5 \mu \mathrm{m}$ and $15.4 \mu \mathrm{m}$ for the impact and fractured specimens, respectively, were obtained from the reconstruction process. These tomographs of the off-axis fractured specimen at the impact and the bending locations are presented in Figs. 11 and 12, respectively. In Fig. 11, the sample shows similar damage modes of matrix cracking, delamination and debonding as in the on-axis specimens. However, the extent of damage is less than in the on-axis specimens. In the off-axis laminates, thicker interlaminar and intralaminar resin-rich regions are present than in the on-axis ones. In these laminates, the elasto-plastic TPU matrix sharing almost $50 \%$ of load with fibres in $\pm 45^{\circ}$ orientation was yielded ahead of the crack tip during cracking and delamination; thus enhancing fracture toughness of the woven composites and suppressing damage. The sample at the bending location in Fig. 12 also highlighted similar damage modes with additional fabric fracture on the tension (impact side) of the specimen. However, due to plasticity, this fracture was not as catastrophic as occurred in the on-axis specimens, pierced in two pieces as shown in Fig. 10. Here, the specimen was intact even after the fracture of fabric on its tension side, as shown in Fig. 12, thanks to intact tows/fibres on the compression side. Therefore, it is evident that pseudo-ductility in the off-axis specimens resulted in damage suppression under dynamic loading.

It is obvious from this analysis that, compared to drop-weight tests, different kinematics of the large-deflection bending resulted in substantial difference in formation of damage modes. In the former, for similar composites, hit with a hemispherical impactor, damage formation is in the form of a cone, beginning from fibre fracture and delamination at the bottom surface and progressing towards the top of the laminate, as inspected in [23, 27]. In this study, at the impact location for the warp specimen in Fig. 9c, the interface on the impact side (specimen's front side) was more damaged than the back side. Additionally, in this study, no fibre fracture occurred at the 
back face, and only minor dents below the striker were observed on the impacted face as shown in Fig. 9. The impact location experienced matrix cracking and delamination as shown in Figs. 9c and d. Here, the fabric fracture was observed only at the bending location.

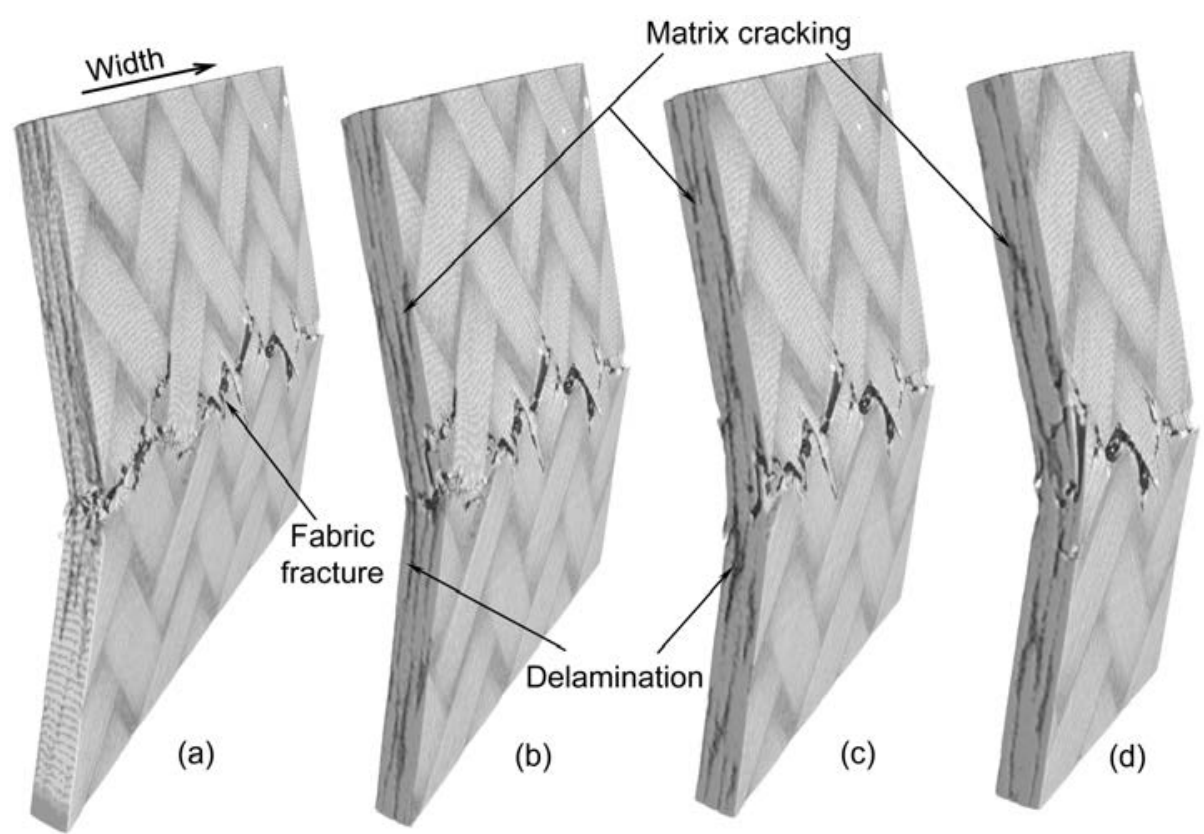

Fig. 12. Tomographic 3D images of off-axis CFRP specimen at bending (fracture) location along the width of sample: (a) full; (b) three-quarter; (c) half; and (d) one-quarter of width

\section{Conclusions}

In this study, experimental tests were first performed to investigate quasi-static behaviour of CFRP laminates in three different configurations of warp, weft and off-axis layups. These tests revealed the high values of strength and modulus but low strains to failure and specific energy absorption of the on-axis laminates as compared to the off-axis laminates. Further, the off-axis laminates demonstrated ductile behaviour before their ultimate failure as compared to linear-elastic stress-strain behaviour of the on-axis laminates, but with lower stiffness and strength. The specimens were then tested under large-deflection dynamic bending at various levels of impact energies up to their ultimate fracture, to replicate the in-service loading scenarios of sports products. Load-time, loaddeflection and energy-time diagrams were used to evaluate the dynamic behaviour of the materials at various energy levels. In the tests of the on-axis (specially orthotropic) laminates, at sub-critical energy levels, the load drops before the peak exhibited damage initiation; whereas the ultimate laminate brittle fracture was characterised by a sudden load drop in the force history plots at the critical energy level. On the contrary, the offaxis specimens exhibited a metals-like ductile behaviour known as pseudo-ductility before their ultimate failure. The off-axis specimens of the same material sustained almost double impact energy of the on-axis specimens making them favourable for high-energy absorption. The material characterisation revealed that for applications demanding strength and stiffness, the on-axis CFRP composites are a better choice. Where energy-absorbing capability is required, the off-axis CFRP laminates are favourable candidates. However, the applications demanding strength, stiffness and energy absorbing as in sports products, a combination of both types of plies as in a quasi-isotropic layup will be an optimum choice. 
Micro-CT analysis of the tested specimens showed that matrix cracking, delamination and tow debonding were the dominant damage modes at the specimen's impact location, whereas at the bending location these modes were coupled with fabric fracture. In the off-axis laminates, damage evolution was suppressed and delayed by their inherent pseudo-ductility, and the specimen's failure was not as catastrophic and sudden as in the on-axis laminates. These characteristics make them suitable for energy-absorption applications with lower safety margins. Further, a substantial difference in damage patterns was found at the impact location between the nonpenetration dynamic bending and drop-weight tests with penetration for the first time. This knowledge of the novel type of a damage-formation pattern under dynamic bending can also be used in tailoring the composite design for such conditions. A better understanding of mechanical behaviour, deformation and damage modes of CFRP composites under quasi-static and dynamic loading conditions was gained in this research, which is required for damage-tolerant design of CFRP laminates for applications in sports products. The effect of repeated impacts (impact fatigue), as observed in various sporting activities, e.g. sports shoes in a marathon race, baseball/cricket bats hit by ball repeatedly, etc. on mechanical behaviour, damage evolution and residual properties of woven laminates used in sports products needs to be studied in future.

\section{References:}

[1] Ullah H, Harland AR, Silberschmidt VV. Damage and fracture in carbon fabric reinforced composites under impact bending. Composite Structures. 2013;101(0):144-56.

[2] Van De Velde K. Textile composites in sports products. In: Shishoo R, editor. Textiles in Sport: Woodhead Publishing; 2005. p. 309-22.

[3] Crabtree P, Dhokia V, Newman S, Ansell M. Manufacturing methodology for personalised symptom-specific sports insoles. Robotics and Computer-Integrated Manufacturing. 2009;25(6):972-9.

[4] Yukawa H, Tokizawa A, Kawamura S. Generating two dimensional ground reaction forces with a viscoelastic runner model. Procedia Engineering. 2011;13:161-7.

[5] Gibbs PJ. Advanced modelling of sports footwear: Loughborough University, UK; 2009.

[6] Hassan MA, Naderi S, Bushroa AR. Low-velocity impact damage of woven fabric composites: Finite element simulation and experimental verification. Materials \& Design. 2014;53(0):706-18.

[7] Rajesh Mathivanan N, Jerald J. Experimental investigation of low-velocity impact characteristics of woven glass fiber epoxy matrix composite laminates of EP3 grade. Materials \& Design. 2010;31(9):4553-60.

[8] Sarasini F, Tirillò J, Valente M, Ferrante L, Cioffi S, Iannace S, et al. Hybrid composites based on aramid and basalt woven fabrics: Impact damage modes and residual flexural properties. Materials \& Design.

2013;49(0):290-302.

[9] Zhang D, Sun Y, Chen L, Pan N. A comparative study on low-velocity impact response of fabric composite laminates. Materials \& Design. 2013;50(0):750-6.

[10] Choudhry RS, Hassan SF, Li S, Day R. Damage in single lap joints of woven fabric reinforced polymeric composites subjected to transverse impact loading. International Journal of Impact Engineering 2015; 80 76-93.

[11] Ly QH, Alaoui A, Erlicher S, Baly L. Towards a footwear design tool: Influence of shoe midsole properties and ground stiffness on the impact force during running. Journal of Biomechanics. 2010;43(2):310-7.

[12] Zadpoor AA, Nikooyan AA, Arshi AR. A model-based parametric study of impact force during running. Journal of Biomechanics. 2007;40(9):2012-21. 
[13] Bull D, Sinclair I, Spearing S, Helfen L. composite laminate impact damage assessment by high resolution 3D X-ray tomography and laminography. $18^{\text {th }}$ International Conference on Composite Materials. Jeju Island, Korea, 2011.

[14] Pernice MF, De Carvalho NV, Ratcliffe JG, Hallett SR. Experimental study on delamination migration in composite laminates. Composites Part A: Applied Science and Manufacturing. 2015;73:20-34.

[15] Ullah H, Harland AR, Silberschmidt VV. Evolution and interaction of damage modes in fabric-reinforced composites under dynamic flexural loading. Composites Science and Technology. 2014;92:55-63.

[16] Vieille B, Casado VM, Bouvet C. About the impact behavior of woven-ply carbon fiber-reinforced thermoplastic-and thermosetting-composites: A comparative study. Composite Structures. 2013;101:9-21.

[17] Ullah H, Harland AR, Silberschmidt VV. Characterisation of mechanical behaviour and damage analysis of 2D woven composites under bending. Composites Part B 2015;75 156-66.

[18] Bergmann T, Heimbs S, Maier M. Mechanical properties and energy absorption capability of woven fabric composites under $\pm 45^{\circ}$ off-axis tension. Composite Structures. 2015;125:362-73.

[19] Ullah H, Harland AR, Blenkinsopp R, Lucas T, Price D, Silberschmidt VV. Analysis of nonlinear shear deformations in CFRP and GFRP textile laminates. Applied Mechanics and Materials. 2011;70:363-8.

[20] Fuller JD, Wisnom MR. Pseudo-ductility and damage suppression in thin ply CFRP angle-ply laminates. Composites Part A: Applied Science and Manufacturing. 2015;69(0):64-71.

[21] Czél G, Pimenta S, Wisnom MR, Robinson P. Demonstration of pseudo-ductility in unidirectional discontinuous carbon fibre/epoxy prepreg composites. Composites Science and Technology. 2015;106(0):110-9. [22] Kazemahvazi S, Schneider C, Deshpande VS. A constitutive model for self-reinforced ductile polymer composites. Composites Part A: Applied Science and Manufacturing. 2015;71(0):32-9.

[23] Evci C, Gülgeç M. An experimental investigation on the impact response of composite materials. International Journal of Impact Engineering. 2012;43:40-51.

[24] Reyes G, Sharma U. Modeling and damage repair of woven thermoplastic composites subjected to low velocity impact. Composite Structures. 2010;92(2):523-31.

[25] López-Puente J, Li S. Analysis of strain rate sensitivity of carbon/epoxy woven composites. International Journal of Impact Engineering. 2012;48(0):54-64.

[26] Hosur M, Adbullah M, Jeelani S. Studies on the low-velocity impact response of woven hybrid composites. Composite Structures. 2005;67(3):253-62.

[27] Atas C, Sayman O. An overall view on impact response of woven fabric composite plates. Composite Structures. 2008;82(3):336-45. 